\title{
Technical and environmental effects of concrete production: dry batch versus central mixed plant
}

\author{
Bogdan Cazacliu*, Anne Ventura \\ Laboratoire Central des Ponts et Chaussées, rte de Bouaye, BP 4129, 44341 Bouguenais cedex, France
}

\section{A R T I C L E I N F O}

\section{Article history:}

Received 8 January 2010

Accepted 30 April 2010

Available online 8 May 2010

\section{Keywords:}

Concrete production

Mixing

Cement saving

Environmental

\begin{abstract}
A B S T R A C T
Current environmental and economical circumstances accelerate the developments of new concrete constituents. Whereas the process technology impacts the mix-design strategy, it seems obvious that manufacturing process is prone to evolutions. This article presents a method to compare environmental and economical consequences of different technological solutions on the basis of the influence on the cement consumption needed for a given concrete performance. Case study is the choice of dry batch or central mixed concrete production systems for a ready mixed concrete production. The theoretical difference in cement consumption is estimated by considering that the water content fluctuation is by far the dominant factor governing the truck to truck variation. The addition of a mixer is effectively found to contribute to cement reduction. Environmental comparison is performed using an EADT indicator (Environmental Amortization Duration Time) defined in the article, and testing various environmental data. The EADT for energy consumption, released $\mathrm{CO}_{2}$ and particles are found below 6 years, in the whole range of tested environmental data for an annual production of $40,000 \mathrm{~m}^{3} \mathrm{yr}^{-1}$, with $2 \mathrm{~m}^{3}$ mixer for the central mixed concrete plant. The $\mathrm{NO}_{x}$ and $\mathrm{SO}_{2}$ EADT results are found sensitive to the releases of the steel plant. The financial amortization duration time corresponding to the purchase of a mixer, is found less than 2 years. Although the chosen application case is simplified, these results encourage further research.
\end{abstract}

(c) 2010 Elsevier Ltd. All rights reserved.

\section{Introduction}

From a low cost and rather unusual material in the late nineteenth century, concrete became "the stone" of the twentieth. From construction elements to urban furniture, a large variety of concrete objects surround us nowadays. Since more than 150 years, research on cement concrete have contributed to improve its mechanicals (strength, durability) and casting (self-compacting...) characteristics.

However, environmental performances of concrete have only recently become a subject of concern. They are often improved by the incorporation of recycled industrial wastes in the mix-design, most recently (Polettini et al., 2009; Bashar and Nounu, 2008), without reducing the quality of the final product. Environmental impacts of cement production have been studied (Josa et al., 2007; Pade and Guimaraes, 2007; Huntzinger and Eatmon, 2009) because it requires high energy consumption and induces important greenhouse gas emissions. Whereas developments of new constituents of

\footnotetext{
* Corresponding author. Tel.: +33 240845656 .

E-mail address: bogdan.cazacliu@lcpc.fr (B. Cazacliu).
}

cement accelerate, cement concrete production processes are only prone to minor evolutions. However, the influence of the process characteristics on the concrete properties (and consequently on the concrete composition needed for a given certified characteristics) are widely recognized, either for high performance or common concretes. In this article, a method to compare environmental and economical consequences of different technological solutions on the basis of the influence on the cement consumption needed for a given concrete performance is presented. Case study is the choice of dry batch or central mixed concrete production systems. These two main processes of ready mix concrete production are compared, with the aim to advance in quantifying the difference in energy consumptions and greenhouse gas emissions.

\section{Concrete production processes}

\subsection{Production variability}

Concrete manufacturer needs to certify that concrete characteristics are respected in the most variable conditions. They should take into account that significant deviations in strength and 
flowability occurs during concrete production. These deviations come from:

- Constituents physical and chemical variability; most often the main effect is those of cement, but water, aggregates and admixture may also have significant effect;

- Process characteristics variation, like temperature, loading sequence, mixing time, transport duration...

- Mix-composition variability.

Several industrial studies - Day (1995) is one of the few published - indicate that the key variability reason is the water content inconstancy, largely before other fluctuations like chemical activity of cement or sand's fines content.

As shown in Cazacliu et al. (2005) the main origin in shifts of water content is the aggregates moisture fluctuation. While sand is expected to present larger water content variations than other aggregates, plants are generally equipped with moisture meters for batch by batch sand humidity monitoring. However, calibration of moisture meters is awkward and important errors may occur in the sand water content estimation (Château et al., 2001). Although gravels water content has lesser amplitude, their humidity is not measured online and the estimation of the amount of water contained in coarse aggregates is also submitted to large errors (Le, 2007).

The ready mixed concrete producer is required to certify a range of flow characteristics (flowability) of the fresh concrete, as well as a minimum compressive strength of the hardened concrete (specified compressive strength) in the most variable conditions. Both flowability and compressive strength are linked to the water content. When submitted to large water content variability, the concrete producers design robust mix-compositions by i) using additional admixtures (for instance cohesion agent for SCC) to decrease the fresh concrete sensitivity to the water content variation, and by ii) increasing cement proportion to ensure that no more than the permissible proportion of tests will fall below the specified concrete strength. Therefore, different water content fluctuation between processes results in different mix-design practice. For instance, Arafah et al. (1997) show that the variability of compressive strength of truck mixing systems tends to be more than that of central plants. These two types of production system are described bellow.

\subsection{Main types of production process}

Concrete production consists of mixing aggregates (sand and gravels), cement (and sometimes other fine elements), water and admixtures, and then molding the obtained mixture. Ready mixed concrete is manufactured in a concrete plant and transported to the building site by the use of truck mounted mixer.

Two main types of production systems are used for ready mixed concrete production. In the so called "central mixed concrete plant" (Fig. 1a), ingredients are poured into a fixed mixer and mixed generally less than $1 \mathrm{~min}$. The resulting mixture is poured into the truck mounted revolving mixer which performs only an additional mixing during transport. A concrete mixing truck volume is usually about $6-9 \mathrm{~m}^{3}$ and several batches are needed to fill it, as typical mixer's volume is 1 or $3 \mathrm{~m}^{3}$. Each batch respects the mix-design composition. However, current practice is to estimate water content in the mixed batch, for instance by using power consumption evolution. The plant operator uses this information to adjust the added water proportioning in the following batches. This method allows adjusting water content in the truck.

While the central mixed concrete plant is sometimes also called "wet batch system", the "dry batch concrete plant" doesn't use a fixed mixer. All ingredients excepting admixture are poured into a buffer, which directly led them into the truck mounted revolving mixer that ensure both mixing and transport (Fig. 1b). The buffer hopper contains all quantity of constituents needed for one truck. The loading of the admixture is generally delayed. The delaying time is used to premix the other constituents into the mixing truck and to estimate the amount of admixture needed to obtain the certified flowability. This method allows correcting the errors in water content by adjusting the admixture quantity into the truck.

In dry batch concrete plant, the error in aggregates moisture estimation is directly converted in a water dosage error. Adjustment in admixture regulates the flowability but have no effect on concrete strength variability. In central mixed concrete both flowability and strength distributions narrow as the water content in the total mixture inside the truck is potentially better controlled. However, it should be noted that the corrections from a batch to another are not yet automatically done. The potential better regularity of the central mixer plants on the dry batch system is not effective for all ready mix production. Further improvements are expected once implemented automatic corrections using for instance algorithms proposed in Le (2007).

\section{Calculation methods for process comparison}

\subsection{Estimation of the difference in mix-composition}

The difference in mix-composition between dry batch and central mixed concrete plants are difficult to be measured in situ, as

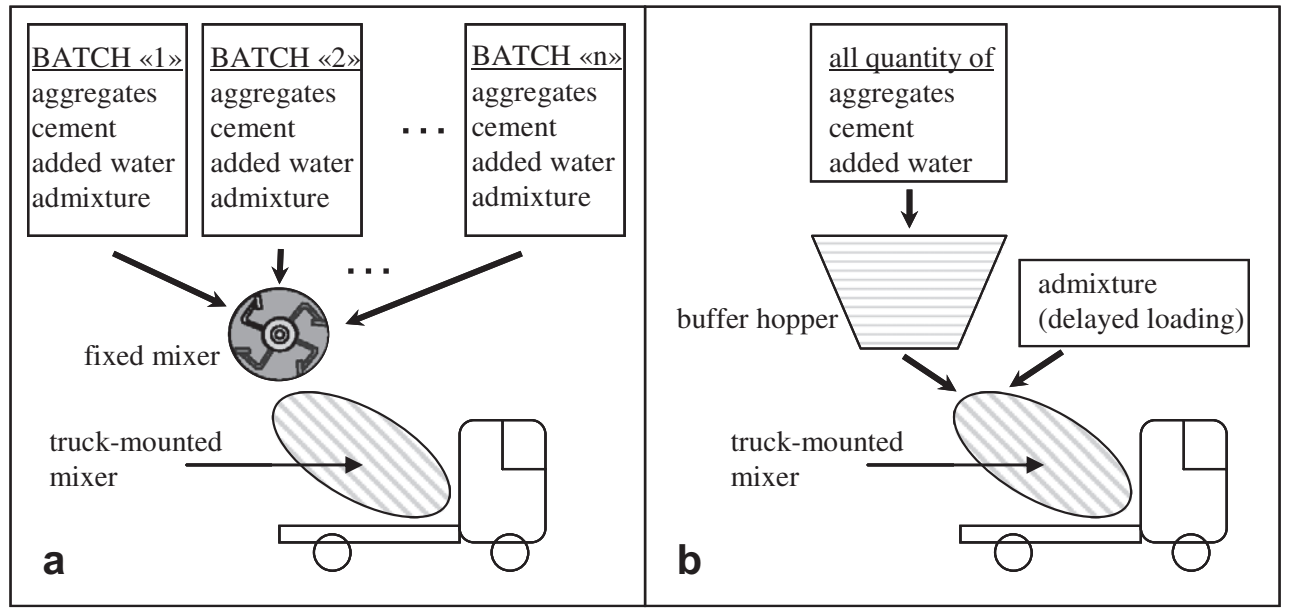

Fig. 1. Main types of manufacturing processes for ready mixed concrete. (a) Central mixed concrete plant and (b) Concrete dry batch plant. 
these processes generally corresponds either to different countries (with different standards and types of concrete constituents) either to different markets (for example ready mix or precast concrete, with different industrial practices). In the following the difference in mean mix-composition is estimated by considering that both production systems needs to certify the same concrete characteristics but have different variations during production.

Strength and flowability are both linked to water content, the main variability origin in production process. As discussed earlier, the flowability variation seems similar in the two processes as it is regulated by an improved water proportioning control in central mixed concrete or by a control of flowability by adapting the admixture proportioning in dry mix system. The method presented here is therefore exclusively based on a strength variability analyses. A reduction in production variability generates a reduction in the mean concrete compressive strength, then in mean cement content needed to guarantee the certified compressive strength.

\subsubsection{Compressive strength variation}

The ACI considers the deviation of the compressive strength $f_{\mathrm{c}}$ as an indicator of the production characterization. ACI 214R-02 (ACI Committee, 2005) shows that the standards of concrete control for general construction testing can vary between excellent (with standard deviation inferior to $2.8 \mathrm{MPa}$ ), good (between 3.4 $\mathrm{MPa}$ and $4.1 \mathrm{MPa}$ ) and poor (superior to $4.8 \mathrm{MPa}$ ). This concerns concrete in the range of $21-34.5 \mathrm{MPa}$ of specified concrete strength.

The European standard EN206-1 doesn't give limits of the strength homogeneity to characterize the concrete production. However, the variation range of the concrete strength seems similar in Europe. This is confirmed, for instance, by the typical range of 3-4 MPa, indicated for the standard deviation of the compressive strength for ordinary concrete by the FNTP in France (FNTP, 2005).

The variability of the compressive strength control - with typical value of the normalized standard deviation $\sigma\left(f_{c}\right)$ of $10 \%$ for a good general construction testing - is considered to be the mean square result of several deviations:

- the within-test variation $\sigma_{\mathrm{T}}\left(f_{\mathrm{c}}\right)$, with the normalized standard deviation considered as $4 \%$ during good field control testing ${ }^{1}$ (ACI 214R-02);

- deviation which origins in other constituents variation, $\sigma_{\mathrm{P}}\left(f_{\mathrm{c}}\right)$; cement chemical activity being one of most important; the magnitude of this error is considered here 4\%;

- the error introduced by the water content fluctuation, $\sigma_{\mathrm{w}}\left(f_{\mathrm{c}}\right)$.

$\sigma^{2}\left(f_{\mathrm{c}}\right)=\sigma_{\mathrm{T}}^{2}\left(f_{\mathrm{c}}\right)+\sigma_{\mathrm{P}}^{2}\left(f_{\mathrm{c}}\right)+\sigma_{\mathrm{W}}^{2}\left(f_{\mathrm{c}}\right)$

Only the error introduced by the water content variability is considered to differ between the dry and wet batch plants. So, this error introduces a difference in mean cement consumption for compensating different compressive strength variability.

\subsubsection{Water content variation}

To estimate the water content variability, the concrete humidity was measured into the mixer during several month of concrete production in an industrial central mixer plant (Le, 2007). The overall standard deviation is $12 \mathrm{l} \mathrm{m}^{-3}$. The measurement system

\footnotetext{
1 ACI 214R-02 also specifies limits for the compressive strength within-test variation during field control testing as excellent (with variation coefficient $\mathrm{CV}\left(f_{\mathrm{c}}\right)$ inferior to 3\%), very good (between 3 and 4\%), good (between 4 and 5\%), fair (between 5 and 6\%) and poor (above 6\%).
}

was previously carefully calibrated (Cazacliu et al., 2008). The within-test standard-variation is about $3 \mathrm{l} \mathrm{m}^{-3}$. The same amount of error is taken into account by the ready mix concrete producers in France, as $10 \mathrm{l} \mathrm{m}^{-3}$ is considered a typical variation of water content from one batch to the next (Schell, 2004). The water content variability also has important consequence in block or paving stone production. These producers tolerate errors of $\pm 11-12 \mathrm{l} \mathrm{m}^{-3}$ (i.e. Schraback, 2009). Taking into account these data from literature, the batch to batch water content deviation (excluding the within-test deviation) is considered in the following $11 \mathrm{~lm}^{-3}$.

This level of error is expected during a long period of production in a dry batch plant or when no correction is made from one batch to another in a central mixed concrete plant. This value is taken as reference of the standard deviation of the truck to truck water content in a dry batch plant, where no correction of the water content is done.

In the central mixed plant it is possible to correct the water content from one batch to another (even if currently this is not systematically done). Indeed, a change of the water addition may be performed by the plant operator in order to correct the mean water content in the truck (error of the first batch is estimated and corrected in the second batch, third batch corrects the error estimated form the first two batches and so on). The previous cited database shows that with this correction, the standard deviation of the truck to truck water content variation should be as low as $41 \mathrm{~m}^{-3}$.

Le (2007) shown that an automatic servo-control system in a central mixed concrete plant may improve the water content regularity into the truck up to $2 \mathrm{l} \mathrm{m}^{-3}$ (standard deviation). This value is not considered here, as it reflects only a potential accuracy. In practice, automatic correction techniques are not currently implemented.

\subsubsection{Cement savings calculation method}

Two classical water-cement ratio $(w / c)$ laws giving the compression strength of the hardened concrete $f_{c}$ exist, Féret (1892) and Abrams (1918) formulas. As discussed by de Larrard (1999), in the range of usual water to cement ratio $(w / c)$ these two lows give close predictions. Although the strength of the concrete is not controlled only by the strength of the paste, experimental data have shown the practical acceptability of this rule within wide limits.

According to the Abrams' formulas the compression strength is expressed as:

$f_{\mathrm{c}}=A B^{w / c}$

where for instance Popovics and Popovics (1995) propose $A=147 \mathrm{MPa}$ and $B=0.0779$.

Féret proposed a proportionality of the compression strength with an expression of the cement, water and air volume contents in the concrete, respectively $V_{\mathrm{c}}, V_{\mathrm{w}}$ and $V_{\mathrm{a}}$ :

$f_{\mathrm{c}} \propto \frac{V_{\mathrm{c}}^{2}}{\left(V_{\mathrm{a}}+V_{\mathrm{w}}+V_{\mathrm{c}}\right)^{2}}$

For plastic concrete, with air content generally inferior to $3 \%$, this expression may be written as:

$f_{c} \propto \frac{1}{(1.25+\rho w / c)^{2}}$

where $\rho$ is the cement's solid density (typically 3.15).

De Larrard suggests a modified Feret's law of the form (de Larrard, 1999): 
$f_{\mathrm{c}} \propto \frac{V_{\mathrm{c}}^{2.85}}{\left(V_{\mathrm{c}}+V_{\mathrm{w}}\right)^{2.85}}$

The fluctuation of the compressive strength may be linked to the water content fluctuation by considering the derivative of the water-cement ratio laws with respect to the water content $w$. The several expressions proposed above give:

$\frac{d f_{\mathrm{c}}}{f_{\mathrm{c}}}=k \frac{d w}{c}$

with $k=\ln B, k=-2 \rho / 1.25+\rho w / c$ or $k=-2.85 \rho / 1+\rho w / c$ from expressions (2), (4) and (5) respectively. By considering $w / c$ between 0.5 and 0.6 and by using the previous given values for $B$ and $\rho$, the value of $k$ is situated between 2 and 3.5.

The relation (6) gives the standard deviation $\sigma_{\mathrm{w}}\left(f_{\mathrm{c}}\right)$ of the compressive strength for a given mix-design of mean strength $f_{\mathrm{c}}$, related to a water content standard deviation $\sigma(w)$ :

$\frac{\sigma_{\mathrm{W}}\left(f_{\mathrm{c}}\right)}{f_{\mathrm{c}}}=k \frac{\sigma(w)}{c}$

The minimum certified compression strength $f_{\text {co }}$, with $u_{\mathrm{p}}$ defining the confidence interval for a given probability $p$ :

$f_{\mathrm{co}}=m\left(f_{\mathrm{c}}\right)-u_{\mathrm{p}} \sigma\left(f_{\mathrm{c}}\right)$

must be ascertained for two different processes, with different water content deviations, $\sigma_{\mathrm{a}}(w)$ and $\sigma_{\mathrm{b}}(w)$ for processes (a) and (b) respectively. Considering $\Delta \sigma(w)=\sigma_{\mathrm{a}}(w)-\sigma_{\mathrm{b}}(w)$, the difference $\Delta m$ $\left(f_{\mathrm{c}}\right)$ in the mean compressive strength between the two processes, for a given mix-design, may be obtained from:

$\frac{\Delta m\left(f_{\mathrm{c}}\right)}{m\left(f_{\mathrm{c}}\right)}=-k u_{\mathrm{p}} \xi \frac{\Delta \sigma(w)}{c}$

where $\xi$ is deduced from equation (1) as:

$\Delta \sigma\left(f_{\mathrm{c}}\right)=\xi \Delta \sigma_{\mathrm{W}}\left(f_{\mathrm{c}}\right)$

For expected standard deviation of water content in the two processes $\xi$ could be considered constant at 0.85 .

The difference in cement consumption may now be deduced by considering the derivative with respect to the cement content of the concrete strength evolution with the water-cement ratio:

$\frac{d f_{\mathrm{c}}}{f_{\mathrm{c}}}=\frac{k w}{c} \frac{d c}{c}$
This relation is valid for the three presented laws (2), (4) and (5) with $k$ defined as previously. The difference in cement consumption is now estimated as follows:

$\Delta c=-\frac{u_{\mathrm{p}} \xi \Delta \sigma(w)}{w / c}$

The cement saving $\Delta c$, the water content $w$, the cement content $c$ and the reduction in water content variability $\Delta \sigma(w)$ are expressed in mass. The relation (12) shows that the process which reduces the water content fluctuation allows a reduction in cement consumption. The cement saving depends only of the water-cement ratio and the risk assumed during the concrete production. The expression $u_{\mathrm{p}} \Delta \sigma(w)$ corresponds to the higher limit of the water content deviation certified for the given $p$-value. Standards generally impose a confidence in the minimum certified compression strength of $95 \%$. This is the case, for instance, of the European standard EN206-1. The corresponding value of $u_{\mathrm{p}}$ is 1.645 . However producers generally increase the confidence interval and $u_{\mathrm{p}}$ should be considered higher, for instance $2(p=97.5 \%)$.

The relation (12) is independent of other mix-design or process constants and is obtained for various laws of concrete strength evolution with water-cement ratio. A large validity domain may be presumed.

3.1.4. Comparison of the mixture composition in the two processes

It is assumed that the cement saving is compensated by an equivalent increase in aggregates content. Also, reduction in the cement content is associated with reduction in the admixture needed in the mix-design. This reduction obviously intensifies the environmental and economical effect of the cement saving, even if this aspect is not discussed here.

\subsection{Environmental assessment methods}

\subsubsection{Environmental system}

Environmental comparison between central mixed process (a) and dry batch process ( $b$ ) has been conducted in accordance with life cycle assessment (ICA) method. However, comparison has been focused on some inventory flows and the impact assessment part of ICA is not performed. The complete environmental system corresponding to cement concrete production is shown on Fig. 2. Quarries produce limestone and clay that are manufactured into cement in a cement plant, and aggregates which are mixed to cement, water and admixtures to obtain concrete. Steel is produced from scrap steel and iron ore in a steel plant, and is used to manufacture the mixer and the plant reinforcement to sustain the mixer.

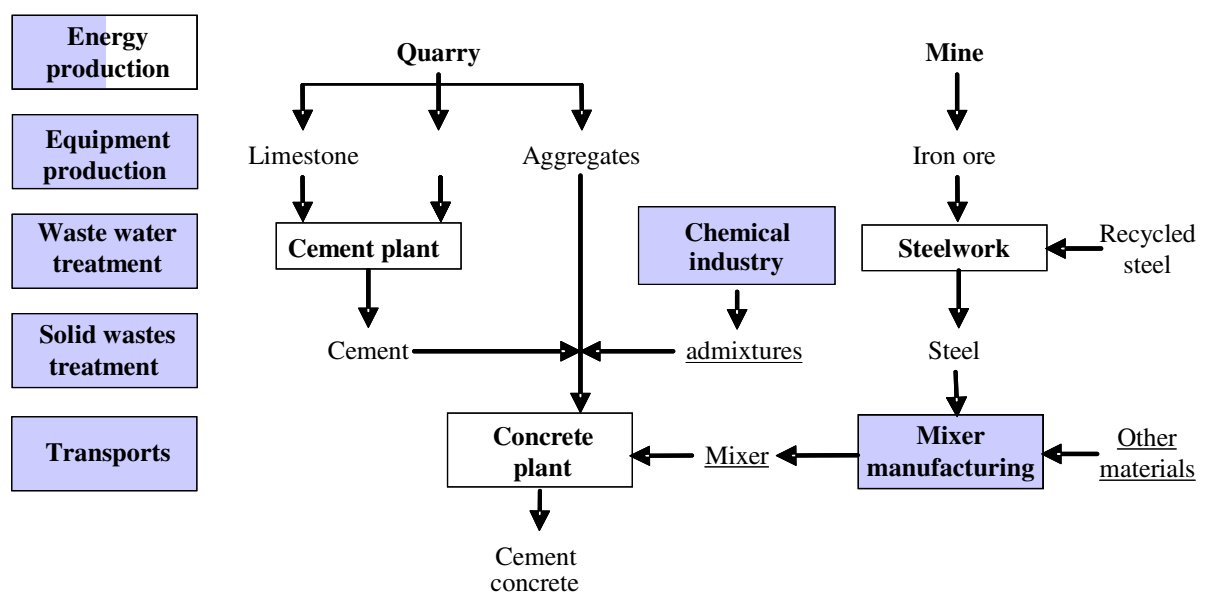

Fig. 2. Scheme of the environmental system. Grey box: process schemed but not included in the system, underlined text: material schemed but not included in the system. 
However, the system has been voluntary restricted to processes that seem relevant for comparison as shown on Fig. 3. Thus, it is limited to materials and processes expected to induce different environmental consumptions or emissions: mix-components production and additional mixer operation.

The comparison of the mixture composition in the two processes is discussed in the paragraph 3.1.4. It results a method to estimate the difference in cement and aggregates consumption. The difference in admixture consumption is neglected because no environmental data were found. However, as discussed in 3.1.4 including them intensifies the effect of a cement saving.

Process (a) requires an additional mixer, therefore the extraction of natural raw materials and production processes necessary for this equipment, should be included in the system. As no specific data on mixers have been found in the literature, it has been assumed that only steel (the main raw material composing the mixer) would be included in the system. Other materials and the production process itself have been neglected.

Among energy production processes, only electricity production has been included. Hence, process (a) requires more electrical power than process (b) because of the mixer's functioning. Then the difference between pollutants emitted by electricity production appeared of interest, for both environmental and economical concerns.

Transports are considered equivalent in the two processes. Indeed, as the same total volume of concrete and mix-components had to be transported from and to the concrete plant, only the truck stay in charge on the concrete production site may be object of difference induced by the production system. In central mixed concrete plants the truck wait several minutes under the plant tower. In dry batch the truck is loaded faster under the plant tower but wait several minutes before the admixture loading. In consequence, the time spend by the truck mixer in the concrete plant is considered similar for the two systems of production and is not analyzed here.

Other connected processes (equipment production, solid wastes and waste water treatments) have also been excluded from the system. These could present differences between process (a) and (b), but their inclusion would have drastically enlarged the system, and was not compatible with the duration of this study. They could be the subject for future researches.

Finally, the service life of cement concrete inside the built structure is not either included in the system, i.e. in the life cycle assessment vocabulary, the study have been limited to a "cradle to gate" approach. The "cradle to grave" approach usually required by the Life Cycle Assessment method, would impose to precisely define the built structure, its service life and maintenance, as well as its end of life. These considerations would simultaneously enlarge the system to a much more complex approach, with reducing the span of the study to the specific studied structure.

\subsubsection{Environmental data and calculations}

Several sources of environmental data (energy consumption, as well as airborne emissions (carbon dioxide $\left(\mathrm{CO}_{2}\right)$, particles, sulphur dioxide $\left(\mathrm{SO}_{2}\right)$ and nitrogen oxides $\left(\mathrm{NO}_{x}\right)$ ) can be found for steel, cement plants and electricity production, and values can be importantly dispersed. Thus, environmental flows calculations have been performed using the minimum and maximum value for each pollutant and for energy, for both processes. Three sources have been collected for steel production: (Stripple, 2001; Häkkinen and Mäkelä, 1996) and International Iron and Steel Institute (IISI, 2002). For cement production, only one source (Josa et al., 2004) has been kept for this article, as it analyses inventory data for 21 cement representative production processes of the EU. The minimum value presented in Table 1 is taken for blast furnace slag cement produced in the Netherlands, whereas the maximum value is taken for Portland SF1 cement produced in Finland. The electrical power consumed by the mixer functioning, as well as by the steel production process, was used to calculate environmental airborne emissions, associated with the average European electricity production processes (MINEFI, 2002).

An annual basis has been used to compare processes. The difference in cement consumption between processes calculation is detailed in the paragraph 3.1. Thus, using cement industry data, annual environmental emissions and consumptions are calculated from saved cement masses. The annual electrical energy consumption has been calculated, using annual time duration and active power of mixer. Active power of mixer is obtained from experimental measurements.

The manufacture of the mixer has been assumed to be equivalent to the production of 10 tons of steel.

Environmental amortization duration times can be calculated similarly to economical ones:

$E A D T_{\mathrm{i}}=\frac{m_{\mathrm{i}}^{\mathrm{s}}}{m_{\mathrm{i}}^{\mathrm{c}}}$

where:

- $E A D T_{\mathrm{i}}$ is the Environmental Amortization Duration Time of the environmental flow $i$ (years)

- $m_{\mathrm{i}}^{\mathrm{s}}$ is the value of the environmental flow $i$ for the initial production of 10 tons of steel ( $\mathrm{kg}$ or $\mathrm{kWh}$ for energy consumption)

- and $m_{\mathrm{i}}^{\mathrm{c}}$ is the value of annual savings of the environmental flow $i$ for the annual production of cement concrete, including cement production ( $\mathrm{kg} / \mathrm{yr}$ or $\mathrm{kWh} / \mathrm{yr}$ for energy consumption).

Table 1

Environmental data and references used for calculations.

\begin{tabular}{|c|c|c|c|c|}
\hline \multicolumn{2}{|l|}{ Process } & \multirow{2}{*}{$\frac{\text { Steel plant }}{\text { Ton of steel }}$} & \multirow{2}{*}{$\frac{\text { Cement plant }}{\text { Ton of cement }}$} & Electricity production \\
\hline Reference unit & & & & kWh \\
\hline \multirow[t]{3}{*}{ Data source } & & Stripple (2001) & (Josa et al. (2004) & MINEFI (2002) \\
\hline & & Häkkinen and Mäkelä (1996) & & Crouail et al. (2000) \\
\hline & & IISI (2002) & & Ottertail power Company (2006) \\
\hline \multirow[t]{2}{*}{ Particles (kg) } & Min. value & 0.21 & 0.2 & 0.0004 \\
\hline & Max. value & 39.20 & 79.60 & \\
\hline \multirow[t]{2}{*}{$\mathrm{SO}_{2}(\mathrm{~kg})$} & Min. value & 0.980 & 0.20 & 0.0015 \\
\hline & Max. value & 7.340 & 0.59 & \\
\hline \multirow[t]{2}{*}{$\mathrm{NO}_{x}(\mathrm{~kg})$} & Min. value & 0.990 & 0.50 & 0.0016 \\
\hline & Max. value & 4.860 & 2.75 & \\
\hline \multirow[t]{2}{*}{$\mathrm{CO}_{2}(\mathrm{~kg})$} & Min. value & 290 & 250 & 0.6117 \\
\hline & Max. value & 2200 & 900 & \\
\hline \multirow[t]{2}{*}{ Energy (MJ) } & Min. value & 720 & 887 & 3.6000 \\
\hline & Max. value & 16,704 & 5530 & \\
\hline
\end{tabular}




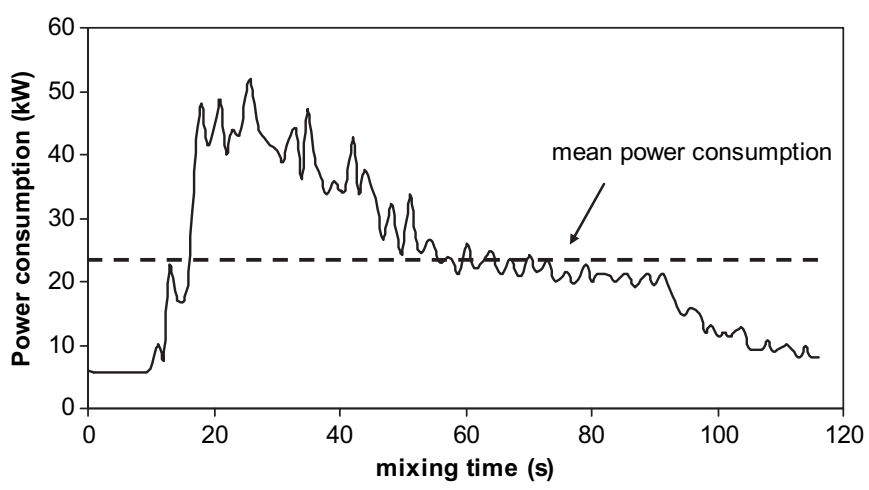

Fig. 3. Example of power consumption evolution with time during a batch.

\subsection{Economical assessment methods}

The economical approach examines costs and benefits from the concrete producer point of view. The economical parameters accounted for, are:

- the investment cost of a mixer,

- additional maintenance costs,

- cement purchase prices,

- electricity consumption costs.

The energy consumption of the mixer for one cubic meter is determined on a database acquired in a case study (Le, 2007). The power consumption time evolution of the mixer during one month is integrated, and then dividing by the number of cubic meters of concrete produced.

Productivity differences between the two processes, difficult to estimate theoretically, are not considered in this study.

Prices and costs values are taken from recent references, thus, they are assumed to be expressed in current euro.

\section{Results: application to a case study}

The comparison between central mixed and dry batch processes is performed on an annual basis. A concrete plant with an annual production of $40,000 \mathrm{~m}^{3}$ per year is considered. The mixer of process (a) is a $2 \mathrm{~m}^{3}$ mixer with a $66 \mathrm{~kW}$ installed power. One batch roughly lasts $2 \mathrm{~min}$, including loading and emptying of the mixer. The mean power consumption during this one batch operation time (Fig. 3) is $22 \mathrm{~kW}$. This value is calculated as indicated in paragraph 3.3 .
The difference in water content standard deviation, between the central mixed and the dry batch systems, is considered of $7 \mathrm{l} \mathrm{m}^{-3}$ (paragraph 3.1.2). By mean of the equation (12), the cement dosage reduction possible in a central mixed plant comparing to a dry batch process is about $20 \mathrm{~kg} \mathrm{~m}^{-3}$.

\subsection{Environmental results}

Results concerning consumptions and airborne emissions are presented in Table 2 below.

Table 2 first shows that results are very different when taking minimum or maximum values from literature. Differences between results when considering minimum or maximum values go from 3 folds to 94 , and from 2.6 to 397 for steel and cement productions respectively.

According to results shown in Table 3, passing from process $A$ to $B$ (see Fig. 1) is not always environmentally interesting. For maximal emissions of the steel plant, EADT reaches 5.8 and 11.5 years for particles and $\mathrm{NO}_{x}$ emissions respectively. Furthermore, if the cement plant causes minimal $\mathrm{SO}_{2}$ emissions, then EADT is never reached, due to important $\mathrm{SO}_{2}$ emissions for the steel production. However, in any other cases, EADT is found below 2 years.

\subsection{Economical results}

The price of cement purchase was varied from 70 to $110 € /$ ton. The additional maintenance related to the mixer is assumed to cost around $0.21 € / \mathrm{m}^{3}$ (information obtained from mixing equipment producers). The electricity consumption costs are taken at the European average of $0.097 € / \mathrm{kWh}$ (VAT and taxes included) (MINEFI, 2006).

Variations of the amortization duration time (ADT) is investigated as a function of initial investment cost of a $2 \mathrm{~m}^{3}$ mixer installation (including some supplementary sensors as the wattmeter). Results are presented in Fig. 4. When initial investment varies from 50 to $150 \mathrm{k} €$, the amortization duration time increases from half a year to 1.5 year, in the case of lower cement price $(70 € /$ ton $)$.

Variations of the amortization duration time as a function of electricity costs, within the range of European prices (MINEFI, 2006), have also been examined. It is not presented here, because it was not found sensitive. It was found almost stable at around one year of amortization duration time, for an $80 \mathrm{k} €$ initial investment. In those conditions, the amortization duration time is found to exceed 4 years when reaching an electricity cost of $4.5 € / \mathrm{kWh}$ which is 46 times higher than the European average of $0.097 € /$ kWh indicated by MINEFI (2006).

ADT (Fig. 4) and EADT (Table 3) are finally found in the same orders of magnitude.

Table 2

Airborne emissions and consumptions from process (a) - process (b) (corresponding to the addition of a mixer).

\begin{tabular}{|c|c|c|c|c|c|}
\hline & \multicolumn{4}{|c|}{ Airborne emissions } & \multirow[t]{2}{*}{ Energy consumption } \\
\hline & Particles & $\mathrm{SO}_{2}$ & $\mathrm{NO}_{x}$ & $\mathrm{CO}_{2}$ & \\
\hline Initial contribution of steel production & \multicolumn{4}{|l|}{$\mathrm{kg}$} & $\mathrm{kWh}$ \\
\hline Min. & 5 & 21 & 21 & 7304 & 230,400 \\
\hline Max. & 454 & 323 & 315 & 124,200 & $1,032,000$ \\
\hline$(\operatorname{Max}-\mathrm{Min}) / \min$ & 94 & 15 & 14 & 16 & 3 \\
\hline Annual savings for cement production & \multicolumn{4}{|l|}{$\mathrm{kg} / \mathrm{yr}$} & $\mathrm{kWh} / \mathrm{yr}$ \\
\hline Min. & -160 & -160 & -400 & $-200,000$ & $-2,784,000$ \\
\hline Max. & $-63,680$ & -472 & -2200 & $-720,000$ & $-15,768,000$ \\
\hline$($ Max. - Min. $) / \min$ & 397 & 1.95 & 4.5 & 2.60 & 4.7 \\
\hline Annual contribution for mixing process & \multicolumn{4}{|l|}{$\mathrm{kg} / \mathrm{yr}$} & $\mathrm{kWh} / \mathrm{yr}$ \\
\hline Mixer operation & $\overline{6}$ & 25 & 27 & 10,398 & $\overline{17,000}$ \\
\hline
\end{tabular}


Table 3

Environmental Amortization Duration Time (see equation (13)) for particles; $\mathrm{SO}_{2}$, $\mathrm{NO}_{x}, \mathrm{CO}_{2}$ emissions, and energy consumption.

\begin{tabular}{lllr}
\hline EADT particles (years) & & \multicolumn{2}{c}{$\begin{array}{l}\text { Initial steel } \\
\text { production }\end{array}$} \\
\cline { 3 - 4 } & & Min. & Max. \\
\hline Annual cement concrete production & Min. & $<0.1$ & 5.8 \\
& Max. & $<0.1$ & $<0.1$ \\
EADT $\mathrm{SO}_{2}$ (years) & & & \\
Annual cement concrete production & Min. & na & na \\
& Max. & 0.1 & 2.2 \\
EADT NO $\mathrm{N}_{x}$ (years) & & & \\
Annual cement concrete production & Min. & 0.8 & 11.5 \\
& Max. & $<0.1$ & 0.2 \\
EADT CO & (years) & & \\
Annual cement concrete production & Min. & 0.1 & 2.0 \\
& Max. & $<0.1$ & 0.2 \\
EADT energy (years) & & & \\
Annual cement concrete production & Min. & $<0.1$ & 0.4 \\
& Max. & $<0.1$ & $<0.1$ \\
\hline
\end{tabular}

\section{Discussion}

Environmentally speaking, the Environmental Amortization Duration Time for released $\mathrm{CO}_{2}$ and particles as well as energy consumption, are found below 6 years, in the whole range of tested environmental data. However, the $\mathrm{NO}_{x}$ and $\mathrm{SO}_{2}$ EADT results are found sensitive to the releases of the steel plant. The variability of steel plants emissions is very important due to various existing technologies such as blast furnaces, electric arc furnaces...

For minimal $\mathrm{SO}_{2}$ releases by the cement plant, EADT is found infinite. Economically speaking, savings of non renewable resources (i.e. energy and raw materials used in cement production), are shown to be in agreement with concrete producers interests: the amortization duration time corresponding to the purchase of a mixer, is found under 2 years. To insure good environmental performances, concrete producers should be aware of the environmental performances of steel production plant.

At the European scale, 369.6 millions of $\mathrm{m}^{3}$ of ready mixed concrete were produced in 2005 , corresponding to 223.84 millions of tons of consumed cement (ERMCO, 2006). Assuming that $50 \%$ of the total European concrete production is performed in plants that are not equipped with fixed mixers, the potential quantity of saved $\mathrm{CO}_{2}$ is of 4,838,064 tons/year. With a total of 6572 millions of tons of $\mathrm{CO}_{2}$ quotas allocated in the EU for the 2005-2007 period (CITEPA, 2005 ), the quantity of saved $\mathrm{CO}_{2}$ corresponds to a $0.074 \%$ decrease of European greenhouse gas emissions. Although total gain appears

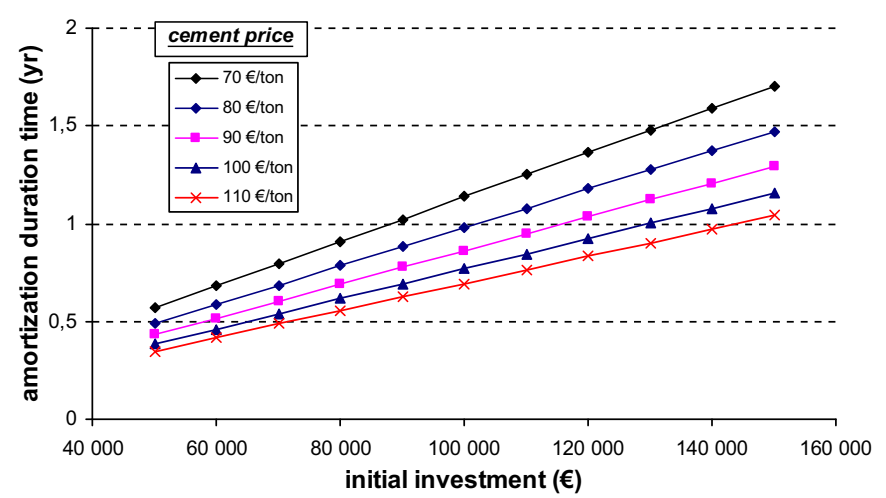

Fig. 4. Amortization duration time (ADT) as a function of initial investment corresponding to process (a). weak, it may be more important at each countries scale. In France, the use of a mixer is mandatory by regulations, thus, the environmental gain can only rely upon the improvement of water proportion accuracy. In other countries, where mixers are not mandatory used, the environmental gain could be much more important.

Several limits of the present theoretical calculation of the cement saving are underlined above. It should be added some complementary remarks. Firstly, dry batch practices may slightly differ from the presented case, i.e. a final correction of water dosage can be manually performed on the construction site. Secondly, it is assumed that the central mixed plant operator applies attentively the added water correction. Finally, standards sometimes impose minimum cement content. This requirement could limit the potential cement saving.

In spite of these limitations, it is clear that the additional mixer is an important tool for the in-line control of the production. If this tool is correctly used the potential cement saving in a central mixed concrete plant makes no doubt and may probably be obtained on most production sites.

The chosen application case is simplified, and it deserves a finer approach considering notably differences in concrete formulations, and technical possibilities of water proportion controls. Furthermore, the change of a process induces other modifications such as logistics (i.e. time of employees for mixer's maintenance and for loading trucks), productivity, wastes and waste treatments... These are not considered here. However, environmental and economical results encourage future research on that topic.

The environmental and economical assessments are based on cement savings only. However, other components are expected to influence the environmental results, in particular admixtures. These are chemical products of which production process may involve non negligible environmental emissions, although they are used in small quantities. Generally speaking, a cement reduction is associated with an admixture reduction, and this could significantly improve environmental performance of concrete. The inclusion of admixtures production into the environmental system would deserve further investigations, if environmental data are available.

The present method to compare environmental and economical consequences of different technological solutions is applicable when evaluating any improvement in process insofar as the cement consumption may be determined. Some examples of processes improvements are the increase of the constituents' dosage reliability (for instance by installing new sensors), the loading sequences optimization or the improvement of the mixing efficiency.

\section{Conclusion}

In spite of recent evolutions in control and dosage systems, concrete production processes tolerate obvious inaccuracies, particularly concerning the water dosage. Aggregates are naturally moistened and their water content has to be monitored to assess total water proportion into the mixture. At this stage, the study is limited to the ready mix concrete production. The cement consumption is compared between a dry batch plant and a central mixed plant.

These two main types of ready mixed concrete manufacturing processes have been compared from technical, environmental and economical point of views, on the basis of identical strength of the final product (hardened concrete). Comparison is performed on the basis of an annual production of $40,000 \mathrm{~m}^{3} \mathrm{yr}^{-1}$. The additional mixer in a wet batch concrete plant is a $2 \mathrm{~m}^{3}$ mixer.

Technically, it is showed that the addition of a mixer contributes to a better control of water proportion in the mixture. The fixed 
mixer of the wet batch system is an effective tool for in-line control of the production. If this tool is accurately used (in practice this is not always the case) a drastic correction of the water content error in the mixing truck is possible. This improved production regularity permits a significant cement proportion reduction, estimated here at $20 \mathrm{~kg} / \mathrm{m}^{3}$.

To perform environmental and economical comparisons, a new environmental indicator, called EADT (Environmental Amortization Duration Time) was created. The environmental assessment was performed taking into account the variability range of Life Cycle Inventories data. The EADT for released $\mathrm{CO}_{2}$ and particles as well as energy consumption, are found below 6 years, in the whole range of tested environmental data. The $\mathrm{NO}_{x}$ and $\mathrm{SO}_{2}$ EADT results are found sensitive to the releases of the steel plant. The financial amortization duration time corresponding to the purchase of a mixer, is found under 2 years. Although the chosen application case is simplified, these results encourage further research.

\section{Acknowledgments}

Couvrot - Skako group and Point P companies are gratefully acknowledged for providing of technical information.

\section{References}

Abrams, D., 1918. Design of Concrete Mixtures. Structural Materials Laboratory Lewis Institute, Chicago, Bulletin No. 1, p. 20.

ACI Committee, 2005. Evaluation of Strength Test Results of Concrete (ACI 214R-02). American Concrete Institute, Farmington Hills, MI, p. 6.

Arafah, A., AbuZaid, M., Siddiqi, G.H., 1997. Truck and central mixing mechanisms in Saudi Arabia: A critical evaluation. ACI Materials Journal 94 (1), 3-9.

Bashar, T., Nounu, G., 2008. Properties of concrete contains mixed colour waste recycled glass as sand and cement replacement. Construction and Building Materials 22, 713-720.

Cazacliu, B., Chopin, D., Shell, R., Château, E., de Larrard, F., Nov. 2005. Water control, homogenization control, transport: three critical stages to obtain consistent SCC. 2nd North American Conference on the Design and Use of Self-Consolidating Concrete and the 4th International RILEM Symposium on Self-Compacting Concrete, Chicago.

Cazacliu, B., Lê, N.D., de Larrard, F., 2008. New methods for accurate water dosage in concrete central mix plants. Materials and Structures 41 (10), 1681-1696.

Château, E., Oudin, J., Cazacliu, B., 2001. Maîtrise du dosage en eau des bétons, mesure de la teneur en eau des granulats. Report SEMR/LCPC for the French national project B@P, 12 pp.

CITEPA Le point sur la politique de l'UE, July-August 2005. "C'est dans l'air", Information Letter of on Regulations, Technical, Scientific and Economic aspects of Air Pollution. Publication from the Interprofessionnal Centre of Technical Studies on Atmospheric Pollution, No. 82, 4 pp.
Crouail, P., Le Dars, A., Schneider, T., Bonnery, C., Grygiel, J-M., 2000. Etude bibliographique sur la comparaison des impacts sanitaires et environnementaux de cinq filières électrogènes, Report from Centre d'Etude sur l'Evaluation de la Protection dans le domaine du Nucléaire (CEPN), contract $\mathrm{n}^{\circ}$ C498/GTIAC, $108 \mathrm{p}$.

Day, K.W., 1995. Concrete Mix Design, Quality Control and Specification. E\&FN Spon. 109-157.

ERMCO, August 2006. European Ready-mixed Concrete Industry's Statistics. Report from the European Ready-mixed Concrete Organization, $11 \mathrm{pp}$.

Féret, R., 1892. Sur la compacité des mortiers hydrauliques. Annales des Ponts et Chaussées 7 (4), 5-164.

FNTP, Fiche 13, mars 2005. Guide d'application pratique de la de la nouvelle norme béton NF EN 206-1 sur les chantiers, 44 pp.

Häkkinen, T., Mäkelä, K., 1996. Environmental adaption of concrete - environmental impact of concrete and asphalt pavements. VTT Research Notes 1752, 93.

Huntzinger, D.N., Eatmon, T., 2009. A life-cycle assessment of Portland cement manufacturing: comparing the traditional process with alternative technologies. Journal of Cleaner Production 17, 668-675.

IISI (International Iron and Steel Institute), October 2002. World steel life cycle inventory. Methodology report 1999/2000, Committee on environmental affairs Brussels, p. 90.

Josa, A., Aguado, A., Heino, A., Byars, E., Cardim, A., 2004. Comparative analysis of available life cycle inventories of cement in the EU. Cement and Concrete Research 34, 1313-1320.

Josa, A., Aguado, A., Cardim, A., Byars, E., 2007. Comparative analysis of the life cycle impact assessment of available cement inventories in the EU. Cement and Concrete Research 37, 781-788.

de Larrard, F., 1999. Concrete Mixture-proportioning, Modern Concrete Technology Series, vol. 9. E\&FN SPON, Londres.

Le, ND., 29 mai 2007. Amélioration de la régularité des béton prêt à l'emploi, PhD theses, ENPC.

MINEFI, 2002. Energies et Matières Premières - Statistiques énergétiques en Europe. Ministère de l'Economie, des Finances et de l'Industrie, Observatoire de l'Economie de l'Energie et des Matières Premières, 7 pp.

MINEFI, 2006. Energies et Matières Premières - Prix du Gaz et de l'Electricité en Europe au 1er janvier. Ministère de l'Economie, des Finances et de l'Industrie. Observatoire de l'Economie de l'Energie et des Matières Premières, 8 pp.

Ottertail power Company, September 2006. Fuel sources air emissions. internet website consulted in. http://www.otpco.com.

Pade, C., Guimaraes, M., 2007. The $\mathrm{CO}_{2}$ uptake of concrete in a 100 year perspective. Cement and Concrete Research 37, 1348-1356.

Polettini, A., Pomi, R., Fortuna, E., 2009. Chemical activation in view of MSWI bottom ash recycling in cement-based systems. Journal of Hazardous Materials 162, 1292-1299.

Popovics, S., Popovics, J.S., 1995. Computerization of the strength versus $w / c$ relationship. Concrete International, 37-40.

Schell, R., déc. 2004. Projet national BAP. Axe 3.1: synthèse fabrication et transport des BAP. IREX, Paris, p. 91.

Schraback, J.M., May 2009. Pour une production économique et écologique de paves en béton avec adjuvants de qualité supérieure. internet website consulted in. SIKA. www.sika.be/bro-sika-paver-fr.pdf.

Stripple, H., 2001. Life cycle assessment of road. A pilot study for inventory analysis. 2nd revised Edition. Report from the IVL Swedish Environmental Research Institute, 96. 